\title{
Safety of early same-admission laparoscopic cholecystectomy for acute mild biliary pancreatitis. A retrospective study for acute pancreatitis
}

\author{
Yunxiao Lyu, Yunxiao Cheng, Bin Wang, Sicong Zhao, Liang Chen \\ Department of Hepatobiliary Surgery, Afliated Dongyang Hospital of Wenzhou Medical University, Dongyang, Zhejiang Province, China
}

Videosurgery Miniinv 2022; 17 (1): 150-155

DOI: https://doi.org/10.5114/wiitm.2021.105575

\begin{abstract}
Introduction: As the standard procedure for the surgical treatment for gallbladder stones, we investigated the controversy surrounding the optimal time for laparoscopic cholecystectomy (LC) for acute mild biliary pancreatitis (AMBP). Aim: To further address the optimal timing of $L C$, we conducted a retrospective study comparing early ( $<72 \mathrm{~h}$, group I) with delayed (> $72 \mathrm{~h}$, group II) LC for AMBP during the same admission.

Material and methods: This retrospective study included medical records of all patients who were admitted with a diagnosis of acute mild biliary pancreatitis at Dongyang People's Hospital from July 2011 to June 2019.

Results: A total of 119 patients were divided into an early LC group (group I; 52 patients) and a control group (group II; 67 patients). Conversion to open cholecystectomy (COC) was performed in 17 patients (6 patients in group I and 11 patients in group II, $p=0.62$ ). There were no significant differences in terms of estimated blood loss and duration of surgery ( $p=0.08$ and $p=0.64$, respectively). The overall hospital stay in group I was significantly shorter than in group II (10.86 \pm 3.21 vs. $13.29 \pm 4.51$ days, $p=0.001)$. Compared with postoperative bile leakage $(p=0.72)$ and postoperative morbidity ( $p=0.97$ ) and mortality, there were no significant differences between the groups.

Conclusions: Early LC during the same admission is safe for acute mild biliary pancreatitis and has the advantage of shortening overall hospital stay. There was no significant increase in COC, bile duct injury, and complications.
\end{abstract}

Key words: acute pancreatitis, laparoscopic cholecystectomy, complication, mild.

\section{Introduction}

Acute pancreatitis, one of the common causes of acute abdomen in the emergency department, is associated with significant morbidity and even mortality $[1,2]$. Acute biliary pancreatitis (ABP) accounts for about $30-55 \%$ of acute pancreatitis [3-5], and around $80 \%$ of affected patients have acute mild biliary pancreatitis (AMBP) [6]. Cholecystectomy is thought to significantly reduce the further incidence of biliary events such as recurrence of ABP, cholecys- titis, and cholangitis [7-11]. During the past few decades, with the development of minimally invasive devices and techniques, laparoscopic cholecystectomy (LC) has become the standard procedure for removal of the gallbladder. However, the major complications of LC include bile duct injury (BDI) among others [12, 13].

A key issue concerning AMBP is the optimal time of $L C$ to treat AMBP. Results from earlier studies and guidelines have led to most recent reports recommending early surgery [14-16]. Such recommenda-

\section{Address for correspondence}

Yunxiao Lyu, Department of Hepatobiliary Surgery, A liated Dongyang Hospital of Wenzhou Medical University, Dongyang 322100 ,

Zhejiang Province, China, e-mail: Ivyunxiao1986@gmail.com 
tions, however, are based on a low level of evidence. On the other hand, the definition of "early" has varied in previous studies and there is no universally accepted definition of "early." The interval for onset of symptoms to surgery varied from $48 \mathrm{~h}$ to 2 weeks. Those in favor of early surgery cite reduction of the recurrence of biliary-related events, shortened hospitalization time, and lower costs $[17,18]$. The opposite view states that early surgery may increase the incidence of postoperative complications resulting from edema. Therefore, the current view on the timing of surgery for AMBP remains unclear.

\section{Aim}

To further address the optimal timing of LC, we conducted a retrospective study comparing early ( $<72$ h) with delayed ( $>72$ h) LC for AMBP during the same admission. In this study, we defined "early LC" as surgery within $72 \mathrm{~h}$ from onset of symptoms. Judgment of the severity of pancreatitis and the preoperative examination of LC can generally be completed within $72 \mathrm{~h}$.

\section{Material and methods}

\section{Patients}

In this retrospective study, the medical records of patients with AMBP from July 2011 to June 2019 were collected. Ethical approval was obtained from the hospital research committee before commencement of the study. Medical measures included age, gender, laboratory findings, body mass index (BMI), American Society of Anesthesiologists (ASA) and perioperative characteristics. The severity of postoperative complications were according to the Clavien-Dindo classification [19].

\section{Inclusion criteria}

The diagnosis of ABP was based on the following criteria: (1) epigastric pain; (2) serum amylase or lipase levels at least three times the upper limit of normal; (3) characteristic findings of acute pancreatitis on cross-sectional abdominal imaging; (4) documented gallstones and absence of other factors known to cause pancreatitis. The severity of ABP was defined by the Bedside Index of Severity in Acute Pancreatitis (BISAP) [20]. Patients with a BISAP score $\leq 2$ were classified as having mild pancreatitis.

\section{Exclusion criteria}

The exclusion criteria were as follows: (1) patients with severe pancreatitis (BISAP $\geq 3$ ); (2) suspected or proven acute cholangitis or common bile duct (CBD) stones; (3) jaundice with total bilirubin $\geq 2 \mathrm{mg} / \mathrm{dl}$; and (4) history of previous abdominal surgery, malignancy, and previous endoscopic retrograde cholangiopancreatography (ERCP).

\section{Treatment}

The patients with AMBP were divided into two groups according to the timing of LC: patients in group I underwent LC within $72 \mathrm{~h}$ from onset of symptoms, and group II patients underwent LC after $72 \mathrm{~h}$. The initial treatment included nil by mouth, fluid and electrolyte replacement, analgesia, oxygen administration, and nasogastric intubation if necessary. Magnetic resonance cholangiopancreatography was performed during the waiting time. All operations were completed by five experienced surgeons with over 10 years of experience. All cholecystectomy procedures were performed laparoscopically with a standard 3- to 4-port technique.

\section{Statistical analysis}

Continuous variables were expressed as mean \pm standard deviation and categorical variables as number and percentage. For categorical variables, the $\chi^{2}$ or Fisher's exact test was performed. We also used Student's t-test for independent groups for comparison with respect to measurable variables. IBM SPSS Chicago, IL Statistics version 22 was used for statistical analyses. $P<0.05$ was considered statistically significant.

\section{Results}

A total of 119 patients with AMBP who underwent LC from July 2011 to June 2019 were retrospectively reviewed. The patients' main characteristic and laboratory values are shown in Table I. The patients' mean age was 60.5 years (range: $30-$ 79 years). According to the inclusion and exclusion criteria, 119 patients were divided into two groups (57 patients in group I and 67 patients in group II). The mean BISAP score was 1.28 in group I and 1.34 in group II. There were no significant differences with respect to mean age, gender, and main laboratory data. The mean thickness of the gallbladder 
Table I. Demographic and clinical characteristics

\begin{tabular}{|lccc|}
\hline Parameter & Group I $(n=52)$ & Group II $(n=67)$ & $P$-value \\
\hline Age $[$ years] & $61 \pm 3.52$ & $60 \pm 2.97$ & 0.55 \\
\hline Sex (male : female) & $29: 23$ & $35: 32$ & 0.84 \\
\hline Gallbladder wall $[\mathrm{mm}]$ & $3.41 \pm 0.3$ & $3.52 \pm 0.6$ & 0.23 \\
\hline Cholecystitis & 9 & 7 & 0.27 \\
\hline Biliary lithiasis & 7 & 6 & 0.43 \\
\hline CBD size $[\mathrm{mm}]$ & $5.5 \pm 1.2$ & $5.7 \pm 1.1$ & 0.39 \\
\hline BISAP score & $1.28 \pm 0.68$ & $1.34 \pm 0.52$ & 0.58 \\
\hline BMI $\left[\mathrm{kg} / \mathrm{m}^{2}\right]$ & $28 \pm 2.13$ & $27 \pm 2.33$ & 0. \\
\hline ASA class $(\mathrm{I}: \mathrm{II}: \mathrm{III})$ & $26: 20: 6$ & $32: 28: 7$ & 0.93 \\
\hline CRP $[\mathrm{mg} / \mathrm{l}]$ & $82.19 \pm 26.45$ & $89.17 \pm 30.19$ & 0.18 \\
\hline WBC $\left[\times 10^{9} / \mathrm{l}\right]$ & $1.85 \pm 1.18$ & $1.92 \pm 1.16$ & 0.75 \\
\hline Glucose $[\mathrm{mmol} / \mathrm{l}]$ & $5.29 \pm 2.64$ & $5.38 \pm 2.73$ & 0.85 \\
\hline AST $[\mathrm{U} / \mathrm{l}]$ & $58.26 \pm 12.68$ & $54.91 \pm 13.18$ & 0.16 \\
\hline TB $[\mu \mathrm{mol} / \mathrm{l}]$ & $12.65 \pm 10.26$ & $15.49 \pm 9.78$ & 0.13 \\
\hline DB $[\mu \mathrm{mol} / \mathrm{l}]$ & $6.64 \pm 6.59$ & $6.69 \pm 7.58$ & 0.97 \\
\hline BMI $\left[\mathrm{kg} / \mathrm{m}^{2}\right]$ & $24.68 \pm 6.59$ & $23.94 \pm 5.58$ & 0.45 \\
\hline Amylase $[\mathrm{U} / \mathrm{l}]$ & $849.32 \pm 67.86$ & $831.45 \pm 72.63$ & 0.17 \\
\hline Lipase $[\mathrm{U} / \mathrm{l}]$ & $798.26 \pm 56.94$ & $803.64 \pm 60.19$ & 0.62 \\
\hline Time to surgery $[\mathrm{h}]$ & $32 \pm 6.89$ & $84 \pm 12.89$ & 0.01 \\
\hline
\end{tabular}

BISAP - bedside index for severity in acute pancreatitis, BMI - body mass index, ASA - American Society of Anesthesiologists, CRP - C-reactive protein, $W B C$ - white blood cells, AST - aspartate aminotransferase, ALT - alanine transaminase, TB - total bilirubin, DB - direct bilirubin.

wall and CBD size were similar in the two groups. Patients in group I underwent LC at a mean of $32 \mathrm{~h}$ compared with $84 \mathrm{~h}$ for those in group II (32 \pm 6.89 vs. $84 \pm 12.89, p<0.01$ ).

Biliary-related events and intraoperative outcomes are shown in Table II. The rate of recurrent pancreatitis was higher in group II than in group I (7 vs. $0, p=0.04$ ). There were no significant differences in terms of duration of surgery and estimated blood loss between the groups (72.18 \pm 29.63 days vs. $69.54 \pm 32.19$ days, $p=0.64 ; 75.49 \pm 19.38 \mathrm{ml}$ vs. $82.19 \pm 21.93 \mathrm{ml}, p=0.08$ ). The number needing drainage in group I was higher than in group II, but without significance $(p=0.65)$ (Table II).

A total of 17 patients underwent conversion to open cholecystectomy (COC) (6 vs. $11, p=0.62$ ), the pattern of which is shown in Table III. The main reason for COC was difficulty in detecting Calot's triangle (4/6 vs. $7 / 11, p=0.68)$. One patient from each group suffered BDI. Open and bile duct-jeju-

Table II. Biliary events and intraoperative outcomes

\begin{tabular}{|lccc|}
\hline Variable & Group I $(n=52)$ & Group II $(n=67)$ & $P$-value \\
\hline Recurrent pancreatitis & 0 & 7 & 0.04 \\
\hline Cholecystitis & 1 & 2 & 0.82 \\
\hline Gallstone colic & 3 & 5 & 1.00 \\
\hline Duration of surgery [min] & $72.18 \pm 29.63$ & $69.54 \pm 32.19$ & 0.64 \\
\hline Estimate blood loss [ml] & $75.49 \pm 19.38$ & $82.19 \pm 21.93$ & 0.08 \\
\hline Drainage & 12 & 7 & 0.11 \\
\hline Duration of drainage [days] & $3.37 \pm 1.25$ & $3.27 \pm 1.18$ & 0.65 \\
\hline
\end{tabular}


num Roux-en-Y were performed in 2 patients. One patient in group I and 2 in group II were found to have obscure anatomy around the gallbladder. One patient in group II suffered uncontrolled bleeding (Table III).

Bile leakage occurred in 4 patients in group I and 3 in group II. These 7 cases were treated with no further invasive procedure and recovered stably. Incision infection was found in 6 patients ( 3 in group I and 3 in group II). According to the Clavien-Dindo classification of postoperative complications, 13 patients were in Grade I-II (6 in group I and 7 in group II, $p=0.91$ ) and 4 were in Grade III-IV ( 2 in each group, $p=0.79$ ). The overall hospital stay was 10.86 days in group I compared with 13.39 days in group II $(10.86 \pm 3.21$ vs. $13.29 \pm 4.51$, $p=0.01)$. No patients required reoperation or readmission, although 2 patients needed postoperative ERCP for CBD stones. Postoperative outcomes are shown in Table IV.

\section{Discussion}

Studies of the treatment of AMBP have shown the importance of $L C$ in reducing the rate of recurrence. However, the optimal timing for $L C$ is yet to be ascertained. The research presented here confirms that early LC during the same admission is safe for AMBP and could shorten the overall hospital stay.

Over the past decades, studies focused on the optimal timing of LC for AMBP have attracted much attention. Owing to the fear of increasing perioperative risks, many surgeons preferred to perform delayed LC after AMBP [21, 22]. However, this approach was associated with higher recurrence of biliary-related events, especially recurrent ABP. A previous meta-analysis showed that $18 \%$ of patients were readmitted after biliary-related events [14]. Therefore, most recent studies advise early LC after AMBP. A prospective study conducted by Aboulian et al. demonstrated that LC within $48 \mathrm{~h}$ of admission is safe [17]. The PONCHO study also showed

Table III. Pattern of COC

\begin{tabular}{|lccc|}
\hline Variable & Group I $(n=52)$ & Group II $(n=67)$ & $P$-value \\
\hline COC: & 6 & 11 & 0.62 \\
\hline Difficult Calot's triangle & 4 & 7 & 0.84 \\
\hline BDI & 1 & 1 & 0.59 \\
\hline Uncontrolled bleeding & 0 & 1 & 0.89 \\
\hline Unclear obscure anatomy $^{a}$ & 1 & 2 & 0.82 \\
\hline
\end{tabular}

COC - conversion to open cholecystectomy, BDI - bile duct injury; ${ }^{a}$ adhesions between omentum, gall bladder, peritoneum, and surrounding tissues around gallbladder.

Table IV. Postoperative outcomes

\begin{tabular}{|c|c|c|c|}
\hline Variable & Group I $(n=52)$ & Group II $(n=67)$ & $P$-value \\
\hline Bile leak & 4 & 3 & 0.72 \\
\hline BDI & 1 & 1 & 0.59 \\
\hline Incision infection & 3 & 3 & 0.92 \\
\hline Total complication & 8 & 9 & 0.97 \\
\hline \multicolumn{4}{|l|}{ Clavien-Dindo classification } \\
\hline Grade I-II & 6 & 7 & 0.91 \\
\hline Grade III-IV & 2 & 2 & 0.79 \\
\hline Mortality & 0 & 0 & \\
\hline Overall hospital stays [days] & $10.86 \pm 3.21$ & $13.29 \pm 4.51$ & 0.001 \\
\hline Re-operation & 0 & 0 & \\
\hline Re-admission & 0 & 0 & 0.59 \\
\hline Postoperative ERCP & 2 & 2 & 0.79 \\
\hline
\end{tabular}

$B D I$ - bile duct injury, $E R C P$ - endoscopic retrograde cholangiopancreatography. 
that same-admission LC could reduce the rate of recurrent biliary pancreatitis [23]. The guideline of the British Society of Gastroenterology recommended LC within 2 weeks of discharge [16], whereas others provided different recommendations. Thus it is unclear whether LC performed within $72 \mathrm{~h}$ from onset of symptoms is safe for AMBP. A recent Cochrane review demonstrated that LC performed within 3 days was safe and could shorten the total hospital stay [24]. To our best knowledge, there are only four randomized controlled trials (RCTs) in the previous literature. It is thus necessary and important to conduct a retrospective study given the difficulty of predicting the progression of pancreatitis. In our retrospective study, LC performed within $72 \mathrm{~h}$ demonstrated safety equal to that performed after $72 \mathrm{~h}$. According to the Clavien-Dindo classification of postoperative complications, there were no significant differences in terms of major complications. BDI and postoperative bile leakage, the main biliary-related complications, showed no differences between our two groups. Most previous studies measured the severity of biliary pancreatitis using the Ranson score. The Ranson criteria require $48 \mathrm{~h}$ for completion, thus missing the potentially valuable early treatment. In 2008, the BISAP was proposed to predict severe acute pancreatitis [20]. Previous studies have demonstrated that the BISAP score is a reliable tool for identifying acute pancreatitis patients $[25,26]$. The present study is the first to use BISAP for classification of pancreatitis, which can potentially shorten the waiting time before surgery.

Consistent with previous research, our study showed that early LC could reduce the rate of recurrent pancreatitis. The study conducted by lto et al. showed that $32 \%$ of patients were readmitted because of pancreatitis while waiting for LC [27]. Another concern about early surgery is that it may increase postoperative ERCP. Two patients from each of our groups underwent postoperative ERCP, with no discernible significant difference. However, future studies with larger samples are necessary.

The possible increase in the COC rate is considered the reason why many surgeons choose delayed LC. Previous studies demonstrated that early LC may be more technically challenging because of the edema and inflammation [28, 29]. This view is changing as laparoscopic technology continues to advance. In a study by Aksoy et al., the main reason for $\mathrm{COC}$ in the early group was obscure anatomy (including Calot's triangle), and no significant differences from the delayed group were observed, in line with the results of our study, where the main reason for $\mathrm{COC}$ was difficulty in detecting Calot's triangle. Compared with later LC, early LC was not associated with an increase in detecting Calot's triangle.

One advantage of early LC is that it leads to a shorter hospital stay. Previous retrospective and prospective studies showed that earlier LC was associated with decreasing stays in hospital [28]. The conclusion of these studies, namely that earlier surgery results in a shorter hospital stay without an increase in complication rates, is consistent with the inference of the present study.

Limitations of our study include the retrospective study design and small ample size considerations. BISAP is mainly used to predict the severity of pancreatitis and for early identification of patients at increased risk for in-hospital mortality. However, BISAP is simpler than other pancreatitis scoring systems, and is now widely used in clinical practice. In addition, patients may preferable to choose early surgery, which could lead to selection bias. More large-scale, high-quality RCTs are required in the future.

\section{Conclusions}

Early LC performed within $72 \mathrm{~h}$ from onset of symptoms is safe for AMBP and has the advantage of shortening the overall hospital stay. There was no significant increase in conversion rate, BDI, and complications. Notwithstanding potential limitations, future high-quality RCTs are necessary.

\section{Acknowledgments}

We would like to acknowledge and thank the native English-speaking biologists who provided medical writing services on behalf of Liwen bianji.

\section{Conflict of interest}

The authors declare no conflict of interest.

\section{References}

1. Peery AF, Crockett SD, Barritt AS, et al. Burden of gastrointestinal, liver, and pancreatic diseases in the United States. Gastroenterology 2015; 149: 1731-41e3.

2. Steinberg W, Tenner S. Acute pancreatitis. N Engl J Med 1994; 330: 1198-210. 
3. Tenner S, Baillie J, DeWitt J, et al. American College of Gastroenterology guideline: management of acute pancreatitis. Am J Gastroenterol 2013; 108: 1400-16.

4. Gullo L, Pezzilli R. Acute pancreatitis is unlikely after morphine administration. Dig Liver Dis 2000; 32: 74.

5. Yadav D, Lowenfels AB. The epidemiology of pancreatitis and pancreatic cancer. Gastroenterology 2013; 144: 1252-61.

6. Banks PA, Freeman ML; Practice Parameters Committee of the American College of G. Practice guidelines in acute pancreatitis. Am J Gastroenterol 2006; 101: 2379-400.

7. Garg SK, Campbell JP, Anugwom C, et al. Incidence and predictors of readmissions in acute pancreatitis: a nationwide analysis. Pancreas 2018; 47: 46-54.

8. Moreau JA, Zinsmeister AR, Melton LJ $3^{\text {rd }}$, et al. Gallstone pancreatitis and the effect of cholecystectomy: a population-based cohort study. Mayo Clin Proc 1988; 63: 466-73.

9. Yadav D, O'Connell M, Papachristou GI. Natural history following the first attack of acute pancreatitis. Am J Gastroenterol 2012; 107: 1096-103.

10. Vetrhus M, Berhane T, Soreide O, et al. Pain persists in many patients five years after removal of the gallbladder: observations from two randomized controlled trials of symptomatic, noncomplicated gallstone disease and acute cholecystitis. J Gastrointest Surg 2005; 9: 826-31.

11. Cakir M, Hut A, Akturk OM, et al. A grey zone of hyperamylasemia following endoscopic retrograde cholangiopancreatography: follow-up and differential diagnosis from acute pancreatitis. Videosurgery Miniinv 2021; 16: 38-44.

12. Giger U, Michel JM, Vonlanthen R, et al. Laparoscopic cholecystectomy in acute cholecystitis: indication, technique, risk and outcome. Langenbeck's Arch Surg 2005; 390: 373-80.

13. Pavlidis TE, Marakis GN, Symeonidis N, et al. Considerations concerning laparoscopic cholecystectomy in the extremely elderly. J Laparoendosc Adv Surg Tech A 2008; 18: 56-60.

14. van Baal MC, Besselink MG, Bakker OJ, et al. Timing of cholecystectomy after mild biliary pancreatitis: a systematic review. Ann Surg 2012; 255: 860-6.

15. American Gastroenterological Association Institute on "Management of Acute Pancreatits" Clinical P, Economics C, Board AGAIG. AGA Institute medical position statement on acute pancreatitis. Gastroenterology 2007; 132: 2019-21.

16. Working Party of the British Society of $G$, Association of Surgeons of Great B, Ireland, et al. UK guidelines for the management of acute pancreatitis. Gut 2005; 54 Suppl 3: iii1-9.

17. Aboulian A, Chan T, Yaghoubian A, et al. Early cholecystectomy safely decreases hospital stay in patients with mild gallstone pancreatitis: a randomized prospective study. Ann Surg 2010; 251: 615-9.

18. Gurusamy KS, Davidson C, Gluud C, et al. Early versus delayed laparoscopic cholecystectomy for people with acute cholecystitis. Cochrane Database Syst Rev 2013; 30: CD005440.

19. Clavien PA, Sanabria JR, Strasberg SM. Proposed classification of complications of surgery with examples of utility in cholecystectomy. Surgery 1992; 111: 518-26.

20. Wu BU, Johannes RS, Sun X, et al. The early prediction of mortality in acute pancreatitis: a large population-based study. Gut 2008; 57: 1698-703.
21. Livingston DH, Capko DM, Elcavgae J, et al. Laparoscopic cholecystectomy in the inner-city hospital. Am Surgeon 1994; 60: 971-4.

22. Yamashita Y, Takada T, Kawarada Y, et al. Surgical treatment of patients with acute cholecystitis: Tokyo Guidelines. J Hepatobiliary Pancreat Surg 2007; 14: 91-7.

23. da Costa DW, Bouwense SA, Schepers NJ, et al. Same-admission versus interval cholecystectomy for mild gallstone pancreatitis (PONCHO): a multicentre randomised controlled trial. Lancet 2015; 386: 1261-8.

24. Gurusamy KS, Nagendran M, Davidson BR. Early versus delayed laparoscopic cholecystectomy for acute gallstone pancreatitis. Cochrane Database Syst Rev 2013; 2: CD10326.

25. Khanna AK, Meher S, Prakash S, et al. Comparison of Ranson, Glasgow, MOSS, SIRS, BISAP, APACHE-II, CTSI Scores, IL-6, CRP, and procalcitonin in predicting severity, organ failure, pancreatic necrosis, and mortality in acute pancreatitis. HPB Surg 2013; 2013: 367581.

26. Chen C, Huang Z, Li H, et al. Evaluation of extrapancreatic inflammation on abdominal computed tomography as an early predictor of organ failure in acute pancreatitis as defined by the revised Atlanta classification. Medicine 2017; 96: e6517.

27. Ito K, Ito H, Whang EE. Timing of cholecystectomy for biliary pancreatitis: do the data support current guidelines? I Gastrointest Surg 2008; 12: 2164-70.

28. Sinha R. Early laparoscopic cholecystectomy in acute biliary pancreatitis: the optimal choice? HPB 2008; 10: 332-5.

29. Palanivelu C, Jani K, Maheshkumar GS. Single-center experience of laparoscopic cholecystectomy. J Laparoendosc Adv Surg Tech A 2007; 17: 608-14.

Received: 20.12.2020, accepted: 21.03.2021. 